\title{
The Transformation of Outdoor Ammonium Nitrate Aerosols in the Indoor Environment
}

\author{
Melissa M. Lunden ${ }^{1 *}$ Kenneth L. Revzan ${ }^{1}$, Marc L. Fischer ${ }^{1}$, Tracy L. Thatcher ${ }^{1}$, \\ David Littlejohn ${ }^{1}$, Susanne V. Hering ${ }^{2}$, and Nancy J. Brown ${ }^{1}$ \\ ${ }^{1}$ Environmental Energy Technologies Division, Lawrence Berkeley National Laboratory, \\ 1 Cyclotron Rd., Berkeley, CA 94720, USA \\ ${ }^{2}$ Aerosol Dynamics Inc., 2329 4th Street, Berkeley, CA 94710, USA
}

\begin{abstract}
Recent studies associate particulate air pollution with adverse health effects; however, the exposure to indoor particles of outdoor origin is not well characterized, particularly for individual chemical species. We conducted a field study in an unoccupied, single-story residence in Clovis, California to provide data and analyses to address issues important for assessing exposure. We used real-time particle monitors both outdoors and indoors to quantify PM-2.5 nitrate, sulfate, and carbon. The results show that measured indoor ammonium nitrate concentrations were significantly lower than would be expected based solely on penetration and deposition losses. The additional reduction can be attributed to the transformation indoors of ammonium nitrate into ammonia and nitric acid gases, which are subsequently lost by deposition and sorption to indoor surfaces. A mass balance model that accounts for the kinetics of ammonium nitrate evaporation was able to reproduce measured indoor ammonium nitrate and nitric acid concentrations, resulting in a fitted value of the deposition velocity for nitric acid of $0.56 \mathrm{~cm} \mathrm{~s}^{-1}$. The results indicate that indoor exposure to outdoor ammonium nitrate in Central Valley of California are small, and suggest that exposure assessments based on total particle mass measured outdoors may obscure the actual causal relationships for indoor exposure to particles of outdoor origin.
\end{abstract}

Index Terms: Aerosols, chemical transformation, nitric acid, ammonia, indoor particulate nitrate, penetration

\footnotetext{
${ }^{*}$ Corresponding Author. Tel: +1-510-486-4891; Fax: +1-510-486-5928;

E-mail address: MMLunden@,lbl.gov; Mail stop 51R0208
} 


\section{Introduction}

An understanding of the underlying causes of the adverse health effects resulting from ambient particulate matter (PM) is of major scientific importance. The correlation of adverse health effects with PM concentrations is based upon data from outdoor regional monitoring sites (Dockery 1993, Pope 1995). Yet most exposures occur indoors. Individuals spend, on average, about $90 \%$ of their time indoors - $70 \%$ of that in homes (Jenkins 1992). Improved assessment of exposure is important to understanding the relationship between PM-2.5 and health. A key element in the assessment of exposure to outdoor PM-2.5 is characterizing the transport and fate of particulate matter of outdoor origin to the indoor environment.

Many investigators have examined the indoor concentrations of particulate mass and gaseous species, including their transport into and out of buildings, emissions and formation indoors, and interactions between pollutants and the building surfaces and air handling equipment (Wallace 1996, Weschler 2000). The mass balance equation for transport into the indoor environment includes terms to capture these various sources, sinks, and transformation factors. For particles, this mass balance can be described by the following equation for the time rate of change of indoor concentration $C_{\mathrm{I} ; \mathrm{i}, \mathrm{j}}\left(\right.$ in $\mu \mathrm{g} / \mathrm{m}^{3}$ ) of species $\mathrm{i}$ and aerodynamic size $\mathrm{j}$

$$
\begin{aligned}
\frac{d C_{I ; i, j}}{d t}= & C_{O ; i, j}\left(P(j) \lambda^{1}+\left(1-\varepsilon_{S}(j) \lambda_{S}\right)\right)-C_{I ; i, j}\left(\lambda+\varepsilon_{R}(j) \lambda_{R}^{2}+k_{d e p}(j)\right)+ \\
& S\left(i, j, T, R H, x_{i}, C_{I ; i, j}, C_{O ; i, j}\right)+F\left(i, j, T, R H, x_{i}\right)+E(i, j)+ \\
& K\left(\dot{j}_{1}^{6}, j_{2}\right)+H(i, \stackrel{7}{j}, R H)
\end{aligned}
$$

where $\mathrm{C}_{\mathrm{O} ; \mathrm{i}, \mathrm{j}}\left(\mu \mathrm{g} / \mathrm{m}^{3}\right)$ is the outdoor particulate concentration. The rates $\left(\mathrm{in}^{-1}\right)$ for air infiltration, forced air supply, and air recirculation are $\lambda, \lambda_{\mathrm{S}}$, and $\lambda_{\mathrm{R}}$, respectively. The penetration factor, $\mathrm{P}$, filtration efficiencies for supply and recirculation air, $\varepsilon_{\mathrm{S}}$ and $\varepsilon_{\mathrm{R}}$, and the deposition rate, $\mathrm{k}_{\mathrm{dep}}\left(\mathrm{h}^{-1}\right)$, are functions of particle size. Term 3 of Eq. 1 corresponds to a phase change, $\mathrm{S}$, between the aerosol and gas phase species that occurs due to differences between the indoor and outdoor environments. It can be a complex function of particle size, species, temperature, $\mathrm{T}$, relative humidity, $\mathrm{RH}$, gas phase concentrations, $x_{\mathrm{i}}$, and particle concentrations. The fourth term, $\mathrm{F}$, is a chemical source term expressing the formation of new particulate material by nucleation due to the presence of gases within the house. The fifth term is a particle emission rate, which will depend upon the source type. The sixth term describes particle size change, $\mathrm{K}$, due to coagulation, and the 
seventh term, $\mathrm{H}$, characterizes particle size changes due to water vapor sorption. This equation neglects other indoor sources such as resuspension.

Equation (1) illustrates the complex nature of the indoor concentrations of particulate matter. Previous studies have measured both indoor and outdoor particle concentrations as well as performed measurements to characterize the house, such as the ventilation rate, in order to understand what fraction of indoor particulate is of outdoor origin and what fraction is emitted or formed indoors. It is difficult to decouple physical loss mechanisms that affect particles of outdoor origin from changes in concentration due to indoor sources or particle chemical reactions. It is often assumed that particulate matter is conserved upon entry into a building. Any additional difference between outdoors and indoors that cannot be accounted for by physical loss mechanisms are attributed to either an indoor source term or larger than expected physical loss mechanisms. Few investigators have incorporated a chemical reaction mechanism into their data analysis (Brauer 1991). Indeed, indoor chemical reactions have been investigated much more vigorously for gas phase species (Weschler 1997, Weschler 2000).

There is no a priori reason to believe that outdoor aerosol would be non-reactive in the indoor environment. Buildings can be considered to be small chemical reaction chambers embedded in the larger outdoor atmosphere with different surface to volume ratios, temperatures, and residence times, which interact with and are influenced by the outside. While the chemical reaction times for aerosols may be assumed to be too long for their reactions to be of importance inside, this has not been confirmed. Phase changes may also affect particle concentrations, and may be rapid with respect to residence times. Vapor sorption or reaction at the surfaces inside the residence may be important to the partitioning of semivolatile constituents between the vapor and particle phases. A number of important aerosol chemical species are prime candidates for continued chemical interactions indoors, including organic carbon and ammonium nitrate.

Ammonium nitrate, $\mathrm{NH}_{4} \mathrm{NO}_{3}$, is a major component of atmospheric aerosol species, particularly in the Western U.S. (Seinfeld and Pandis 1998, NARSTO Report 2003). Chow (1993) indicated that it accounts for $25 \%$ of the annual aerosol mass in the San Joaquin Valley. Ammonium nitrate is volatile, existing in equilibrium with its gas phase constituents, ammonia $\left(\mathrm{NH}_{3}\right)$ and nitric acid $\left(\mathrm{HNO}_{3}\right)$. This process is described by the reactions 
Lunden et al.

$$
\begin{aligned}
& \mathrm{NH}_{4} \mathrm{NO}_{3}(\mathrm{~s}) \leftrightarrow \mathrm{HNO}_{3}(\mathrm{~g})+\mathrm{NH}_{3}(\mathrm{~g}), \\
& \mathrm{NH}_{4}^{+}(\mathrm{aq})+\mathrm{NO}_{3}{ }^{-}(\mathrm{aq}) \leftrightarrow \mathrm{NH}_{3}(\mathrm{~g})+\mathrm{HNO}_{3}(\mathrm{~g}) .
\end{aligned}
$$

The equilibrium constants for (2) and (3) depend on ambient temperature and relative humidity. Temperature and relative humidity also impact the physical state of the $\mathrm{NH}_{4} \mathrm{NO}_{3}$ particles, which deliquesce at approximately $60 \%$ relative humidity at ambient temperatures. Experimental investigations of the thermodynamics of ammonium nitrate in the atmosphere have generally confirmed the soundness of equilibrium assumption.

To investigate the dynamics of the transport and fate of outdoor particles in the indoor environment, we performed a controlled series of intensive field experiments using an unoccupied, single-story residence in Clovis, California, a suburb of Fresno, in California's San Joaquin Valley. The conditions in the residence were manipulated to investigate a wide range of conditions during several weeks of intensive measurements. The measurements focused on providing data on indoor and outdoor concentrations of PM-2.5 particles as a function of chemical concentration under a variety of house ventilation, heating and cooling conditions. Indoor sources were minimized to reduce their confounding effect on indoor concentrations.

In this paper, we report on measurements of nitrate aerosol and gaseous ammonia and nitric acid performed under a range of experimental conditions. The measurements are interpreted using a transient mass balance model that includes physical loss terms and ammonium nitrate phase transformations. The phase transformation is modeled using a particle evaporation model. Concentrations of $\mathrm{NH}_{3}$ and $\mathrm{HNO}_{3}$ in the house are calculated from coupled mass balance models, with the particle evaporation serving as a source term. The model is shown to be reasonably successful in reproducing both measured indoor ammonium nitrate and nitric acid concentrations. The effect of temperature, air change, and indoor concentrations on the phase change will be discussed. The results have important implications concerning indoor exposures to ammonium nitrate aerosol.

\section{Methods}

\subsection{Experimental}

The experimental facility is a three-bedroom, single-story home $\left(134 \mathrm{~m}^{2}\right)$ constructed in 1972. The house has standard height ceilings $(2.4 \mathrm{~m})$, a forced air heating and cooling system, and ceiling fans. The structure is of wood-frame construction over a crawl space. All the floors were carpeted, with the exception of linoleum in the kitchen and 
bathrooms. The rooms were lightly furnished. The house is located in a residential suburb, surrounded by homes of similar size and mature trees. The flat topography of the area combined with the mature vegetative growth near the home resulted in low levels of wind loading around the building.

The chemical concentrations of indoor and outdoor aerosols were measured simultaneously with 10-minute time resolution using the integrated collection and vaporization cell (ICVC) system of Stolzenburg and Hering (2000). Particles were collected by humidification and impaction and analyzed by in-situ flash vaporization of the evolved vapor compounds. Nitrate concentrations were measured from the evolved vapors using a chemiluminescent monitor equipped with a molybdenum catalyst to convert higher oxides of nitrogen to nitric oxide. The sulfate quantization was performed by analysis of the evolved sulfur dioxide by UV-fluorescence and total carbon was converted to carbon dioxide and analyzed by nondispersive infrared absorption. A fourcell ICVC system was used to perform simultaneous indoor and outdoor measurements; one pair for nitrate and one pair for a combined carbon and sulfate measurement. The system was located in the living room of the house; however, the outdoor sampling cells were housed in an enclosure ventilated with outdoor air to maintain the system at outdoor temperature.

Gas phase ammonia, nitrous acid, nitric acid and sulfur dioxide were measured using an automated on-line ion chromatograph (IC) system as described by Fischer et al. (2003). Briefly, the IC system collected water-soluble gases both indoors and outdoors using wet effluent denuders, and measured the collected ions using separate anion and cation chromatographs with 30-minute time resolution.

Ventilation rates were measured using continuously released sulfur hexafluoride $\left(\mathrm{SF}_{6}\right)$ as a tracer gas, measuring the concentration using a photoacoustic analyzer (Breul \& Kajer, Model 1302). Temperature and relative humidity were measured both inside and outside the house using dual temperature and relative humidity probes (Vaisala HMD70Y) mounted in aspirated shielded enclosures.

Experiments were conducted during three intensive measurement periods; October 9-23, 2000, December 11-19, 2000 and January 16-23, 2001. During these intensives, entry into the house was limited to a one-hour period at midday to perform instrument checks and flow calibrations. Instrument control and data acquisition for all instruments were 
performed from outside the house, allowing for minimal disturbance of the indoor environment. Using the house as a laboratory, a range of conditions was explored during the intensives by manipulating the ventilation rate and indoor-outdoor temperature gradient through natural or mechanical means. The house experienced infiltration rates in the range of 0.2 to 0.5 air changes per hour $(\mathrm{ACH})$ when allowed to operate under naturally occurring conditions. When the doors and windows were opened, the ventilation rate could increase up to $1 \mathrm{ACH}$. In order to further expand the experimental parameter space to a regime where the residence time for air in the house approached the time required for other processes, such as deposition, to occur, we utilized mechanical ventilation techniques to achieve rates in the range of 2 to $6 \mathrm{ACH}$. The forced-air heating/cooling system was used to provide changes in the indoor/outdoor temperature differential and to provide conditions of either no, continuous, or intermittent fan operation. The filters in the house air handling system were not modified before the study and are typical of residential installations that generally provide low filtration efficiency for PM-2.5.

\subsection{Ammonium Nitrate Evaporation Rate}

When an ammonium nitrate particle penetrates into the indoor environment, it is subjected to temperature and relative humidity conditions that are typically different from the outdoors. Due to interaction with surfaces and possible indoor reactions, the indoor concentrations of $\mathrm{NH}_{4} \mathrm{NO}_{3}$ and its gas phase counterparts, ammonia and nitric acid, will differ from those measured outdoors. The ammonia nitrate system may not be in equilibrium under these new indoor conditions, causing the reaction to shift in the direction necessary to reach equilibrium in its new surrounding. In the case where the equilibrium shift favors the production of gas phase species, there will be mass transport of gases via diffusion away from the particle (Seinfeld 1998).

The rate of evaporation is calculated using mass transfer equations for the transition regime, which describes the case where particle diameters are of the same order as the mean free path of air. Neglecting latent heat effects and assuming dilute conditions, the diffusive molar flux from the particle in moles $\mathrm{s}^{-1}$ is given in Seinfeld and Pandis (1998) as

$$
J_{i, D_{0}}=-2 \pi D_{p} D_{i, a i r} F\left(K n, \alpha_{i}\right)\left(c_{i}^{\infty}-c_{i}^{s}\right),
$$

where $D_{p}$ is the particle diameter, $D_{i, a i r}$ is the diffusivity of gas $i$ in air, $c_{i}^{s}$ and $c_{i}^{\infty}$ are the concentration of the species at the particle surface and in the room, respectively. $K n$ 
is the Knusden number, $K n_{i}=2 \lambda_{i} / D_{p}$, where $\lambda_{i}$ is the mean free path of molecules of gas $i$. The function, $F\left(K n, \alpha_{i}\right)$, allows us to move through the transition regime from the continuum boundary, corresponding to particle diameters much larger than the mean free path, to the kinetic boundary, when particle diameters are smaller than the mean free path. It has been derived by Fuchs and Stutgin (1971) for this purpose, and can be expressed as:

$$
F\left(K n_{i}, \alpha_{i}\right)=\frac{1+K n_{i}}{1+0.3773 K n_{i}+1.33 K n_{i}\left(1+K n_{i}\right) / \alpha_{i}}
$$

where $\alpha_{\mathrm{i}}$ is the mass accommodation coefficient for gas $i$.

The change in size of the ammonia nitrate particle can be calculated using the theory detailed by Wexler and Seinfeld (1990) and Dassios and Pandis (1999). The concentrations of both ammonia and nitric acid are assumed to be in thermodynamic equilibrium with the particle at the particle surface. This equilibrium product associated with reaction (2) is equal to the product of the gas phase concentrations.

$$
c_{\mathrm{NH}_{3}} \cdot c_{\mathrm{HNO}_{3}}=K(T, R H)
$$

This equilibrium product must be corrected for the Kelvin effect. The Kelvin effect accounts for the fact that the vapor pressure over a curved surface exceeds that over a flat surface by a factor of $\exp \left(\sigma v_{l} / R T D_{p}\right)$. The stoichiometry of Eq. (2) requires that the molar flux of $\mathrm{HNO}_{3}$ and $\mathrm{NH}_{3}$ away from the particle must equal the molar consumption of $\mathrm{NH}_{4} \mathrm{NO}_{3}$ from the particle, or

$$
-J_{\mathrm{NH}_{3}, \mathrm{D}_{p}}=-J_{\mathrm{HNO}_{3}, D_{p}}=J_{\mathrm{NH}_{4} \mathrm{NO}_{3}, D_{p}}
$$

Combining the two boundary conditions gives the following transition-regime rate of evaporation from or condensation onto ammonia nitrate particles as;

$$
J_{\mathrm{NH}_{4} \mathrm{NO}}=4 \pi D p\left(\beta+\sqrt{\gamma+4 D_{\mathrm{HNO}_{3}} D_{\mathrm{NH}_{3}} F\left(K n_{\mathrm{HNO}_{3}}\right) F\left(K n_{N H_{3}}\right) K(T, R H) \exp \left(\frac{\sigma v_{l}}{R T D_{p}}\right)}\right)
$$

where $\beta$ and $\gamma$ are given by

$$
\begin{aligned}
& \beta=D_{\mathrm{HNO}_{3}} c_{\mathrm{HNO}_{3}}^{\infty} F\left(\mathrm{Kn}_{\mathrm{HNO}_{3}}\right)+D_{\mathrm{NH}_{3}} c_{\mathrm{NH}_{3}}^{\infty} F\left(K_{N_{H_{3}}}\right), \\
& \gamma=\left[D_{\mathrm{HNO}_{3}} c_{\mathrm{HNO}_{3}}^{\infty} F\left(K_{\mathrm{HNO}_{3}}\right)-D_{\mathrm{NH}_{3}} c_{\mathrm{NH}_{3}}^{\infty} F\left(K_{\mathrm{NH}_{3}}\right)\right]^{2} .
\end{aligned}
$$

A mass balance on the particle converts the molar flux into the rate of change of the particle size 
Lunden et al.

$$
\frac{d}{d t}\left(\rho \frac{\pi}{6} D_{p}^{3} f_{\mathrm{NH}_{4} \mathrm{NO}_{3}}\right)=J_{\mathrm{NH}_{4} \mathrm{NO}_{3}} M_{\mathrm{NH}_{4} \mathrm{NO}_{3}}
$$

where $M_{\mathrm{NH}_{4} \mathrm{NO}_{3}}$ is the molecular weight of ammonium nitrate, $\rho$ is the particle density, and $f_{\mathrm{NH}_{4} \mathrm{NO}_{3}}$ is the mass fraction of the particle that is ammonium nitrate. Both the particle density and the mass fraction of ammonium nitrate are a function of relative humidity as the particle absorbs water at and above the deliquescence relative humidity. The mass fraction of the aerosol constituents is calculated from the molality of the solution at a given relative humidity. A formulation for the change in density as a function of relative humidity can be found in Tang (1981).

\subsection{Indoor Dynamics of Outdoor Pollutants}

The indoor concentrations of particles of specific size and chemical composition can be described using the mass balance model shown in Eq. (1). In applying this model to the ammonium nitrate system, we assume that the coagulation (term 5) and hygroscopic growth (term 6) have a negligible impact on indoor particle concentrations. We further assume that the chemistry in the ammonium nitrate/ammonia/nitric acid system occurs on the existing particles. This precludes the formation of new particles, and allows us to neglect the formation term (term 4) of the mass balance model. The experiment was specifically planned to minimize indoor sources, so we assume that we can neglect term 5. While we expect the air heating system to effect the indoor concentrations of aerosols, we have not included this in the nitrate analysis. Analysis of the sulfate data showed that the effect of the heating system on particle loss rates was small. The phase change term, term 3, can be approximated as a first order reaction

$$
S\left(i, j, T, R H, x_{i}, C_{I ; i, j}, C_{O ; i, j}\right)=-\frac{1}{\tau_{\text {evap }}} C_{\mathrm{NH}_{4} \mathrm{NO}_{3}(a)} .
$$

Thus, the mass balance equation reduces to the form

$$
\frac{d C_{I ; N H_{4} \mathrm{NO}_{3}}}{d t}=C_{O ; \mathrm{NH}_{4} \mathrm{NO}_{3}} \hat{P} \lambda-C_{I ; N \mathrm{~N}_{4} \mathrm{NO}_{3}}\left(\lambda+\hat{k}_{\text {dep }}\right)-\frac{1}{\tau_{\text {evap }}} C_{I ; N \mathrm{NH}_{4} \mathrm{NO}_{3}}
$$

where $\hat{P}$ and $\hat{k}_{\text {dep }}$ are a single value representative of the mass median diameter of ammonium nitrate.

The change in the gas phase concentrations of ammonia and nitric acid in the residence can each be described by a similar equation,

$$
\frac{d C_{I ; l}}{d t}=C_{O ; l} P(l) \lambda-C_{I ; l}\left(\lambda+v_{d e p, l} \frac{S}{V}\right)+\frac{1}{\tau_{\text {evap }}} C_{I ; \mathrm{NH}_{4} \mathrm{NO}_{3}} \frac{R T}{M_{\mathrm{NH}_{4} \mathrm{NO}_{3}} P}
$$


where $C_{I ; l}$ and $C_{O ; l}$ are the indoor and outdoor concentration of gas $l$ in ppb, respectively, $v_{d e p, l}$ is the deposition velocity of gas $l \mathrm{in} \mathrm{m} / \mathrm{s}$, and $S / V$ is the surface to volume ratio of the residence in $\mathrm{m}^{-1}$. Eq. (14) is similar to the particulate mass balance formulation, where the gas is transported indoors from outdoors with a penetration efficiency of $P(l)$, and lost from the residence by exfiltration and deposition. The last term describes the rate of increase in concentration of gas $l$ due to the evaporation of the ammonium nitrate particles by taking into account the stoichiometry of Eq. (2).

Eqs. (13) and (14) are a set of coupled rate equations describing the rate of change of particulate ammonium nitrate and gaseous ammonia and nitric acid. The set of equations was solved using a 'forward-marching' numerical scheme, with a time step of 10 minutes, which corresponds to the measurement interval for the ICVC system. The evaporation time, $\tau_{\text {evap}}$, was evaluated at each time step by solving Eq. (11) using the measured values of temperature and relative humidity as well as the current values of the indoor gas concentrations. An initial particle size of $0.5 \mu \mathrm{m}$ was assumed for the ammonium nitrate particles, based on measurements of the nitrate size distribution for southern California (Wall 1988, John 1990). Correspondingly, a penetration coefficient of 0.8 and a deposition rate coefficient of $0.12 \mathrm{~h}^{-1}$ were used based upon experiments performed in the research house (Thatcher 2002). A penetration coefficient of 1 was assumed for ammonia. Penetration coefficients for nitric acid of 0 and 1 were used for air change rates less than $3 \mathrm{~h}^{-1}$ and greater that $3 \mathrm{~h}^{-1}$, respectively. The latter value of 1 is justified because high ventilation rates were obtained using a fan mounted in the master bedroom window (Lunden 2003).

\section{RESULTS AND DISCUSSION}

Figure 1 shows time series of concentrations of sulfate and nitrate aerosol measured with the ICVC system for two days from the fall and winter intensive measurement periods. Fig. 1 also shows the ventilation rate and indoor temperature measured during the same periods. The ventilation rates measured from noon to midnight on the $18^{\text {th }}$ of October and from noon to midnight on the $16^{\text {th }}$ of December reflect the high values achieved using mechanically driven ventilation. The oscillations in temperature on the $17^{\text {th }}$ of December indicate the cycling of the heating system during a period of heating. There is a great deal of variability in the indoor and outdoor concentrations of both sulfate and nitrate, as well as a difference between the indoor and outdoor concentrations. In general, however, the difference between the indoor and outdoor concentration decreases appreciably during periods of high air change rates, particularly for the sulfate aerosol. 
The most striking feature of the data is that the difference between indoor and outdoor nitrate concentrations is much greater than that measured for sulfate, despite expected similarities in particle size ranges. Sulfate is generally considered to be stable upon transport from outdoors to indoors. The large decrease in indoor nitrate concentration compared to those measured outdoors clearly indicates a shift in equilibrium toward the gas phase within the house.

The importance of the ammonium nitrate dissociation reaction is further demonstrated in Fig. 2, which shows results of the ICVC system for particulate nitrate and gas phase ammonia and nitric acid measured by the automated IC system for four different 12 hour periods during the January intensive. The indoor environment for each 12 hour period was manipulated as follows: (1) ventilation rate of approximately $4 \mathrm{~h}^{-1}$ with the heat off, (2) $\mathrm{ACH} \sim 5 \mathrm{~h}^{-1}$ with the heat on at $20 \mathrm{C}$, (3) $\mathrm{ACH} \sim 0.3 \mathrm{~h}^{-1}$ with the heat off, and (4) ACH $\sim 1 \mathrm{hr}^{-1}$ with the heat off. Note the correlation in outdoor ammonia and outdoor nitrate measurements, particularly on Jan $20^{\text {th }}$. During the period from noon on January $19^{\text {th }}$ to noon on Jan $20^{\text {th }}$, the indoor ammonia levels are correlated with the difference between the indoor and outdoor nitrate levels; when the outdoor nitrate aerosol concentration is much higher than inside, the indoor ammonia concentration is higher than during other periods. Indeed, throughout the entire measurement campaign, the indoor ammonia levels were often higher than those found outdoors due to nitrate dissociation. During periods (1) and (2), the characteristic time for nitrate penetration from outdoors was large enough to balance the amount lost to dissociation, resulting in relatively large indoor nitrate levels. This was one of the few periods when significant levels of indoor nitrate were observed. The addition of heat to the house between conditions (1) and (2) is enough to cause a perceptible shift in equilibrium towards the gas phase. When the air change rate was drastically lowered between conditions (2) and (3), much of the nitrate dissociated, thereby increasing the indoor ammonia concentrations.

Figure 2 shows that the measured indoor nitric acid concentrations were much lower than those measured for ammonia. Indeed, the nitric acid concentration indoors was low to undetectable throughout the entire experiment. Based on Eqs. (2) and (3), equal amounts of ammonia and nitric acid are formed initially, however, the data show a large difference between the indoor concentrations of these two gases. This is consistent with the hypothesis that the gas phase nitric acid is sorbing to the walls at faster rates than the ammonia, which appears to accumulate in the gas phase. We attribute this to acid-base 
chemistry that allows the nitric acid preferentially to sorb to the walls. The loss of gas phase nitric acid indoors serves to continue to drive the equilibrium toward the right.

The times required for evaporation of an ammonium nitrate aerosol particles calculated by the solution of Eq. (11) are shown in Fig. 3. The graphs show the evaporation time as a function of temperature for five indoor ammonia concentrations ranging from 5 to 25 ppb. Figs. $3 \mathrm{a}$ and $3 \mathrm{~b}$ show results calculated for 0.1 and $0.2 \mathrm{ppb}$ of nitric acid, respectively. The results show that the time required for particle evaporation, $\tau_{\text {evap, }}$, is a strong function of all three variables. A change in temperature of $10 \mathrm{C}$ can change the evaporation time by an order-of-magnitude, and an increase in indoor ammonia concentrations from $5 \mathrm{ppb}$ to $25 \mathrm{ppb}$ has a comparable effect. At the temperatures most often found indoors ( 20 to $25 \mathrm{C}$ ), the evaporation time ranges from a few to tens of minutes. The reciprocal of the time required for evaporation, $1 / \tau_{\text {evap }}$ as used in Eq. (14), can be termed an evaporation rate and can be compared to the other important time scales associated with processes in the house. The deposition rate coefficient for the $0.5 \mu \mathrm{m}$ particles is $0.12 \mathrm{~h}^{-1}$, and the ventilation rate ranges from 0.3 to $6 \mathrm{~h}^{-1}$. The calculated evaporation rates for the experimental conditions range from a minimum of $0.3 \mathrm{~h}^{-1}$ to a maximum of $18 \mathrm{~h}^{-1}$. These values are of the same order of magnitude for the other loss rates in the house, indicating that the kinetics of particle evaporation can play a significant role in determining the indoor ammonium nitrate concentrations.

Figure 4 shows the evaporation rate, $1 / \tau_{\text {evap }}$, calculated for the week long intensive measurement period in January, 2001. The figure also includes the indoor temperature and air change rate for the same time period. The results show that the evaporation rate is a strong function of temperature; higher temperatures result in faster evaporation rates. The ventilation rate is also an important variable; for example at noon on January $20^{\text {th }}$, the temperature does not change significantly, while the air change rate drops precipitously, resulting in an increase in the evaporation rate. Lowering the air change rate reduces the concentration of nitric acid indoors since it decreases the particulate nitrate infiltration rate thereby reducing the nitric acid source term - while the loss rate of nitric acid to the house surfaces remains unchanged.

The predicted indoor ammonium nitrate aerosol concentrations are compared with measured indoor nitrate in Fig. 5 for the same January intensive measurement period. The figure also includes the indoor temperature and air change rate for the same time period. The agreement between the model results and the measured indoor ammonium 
nitrate concentrations is quite good. The fit is particularly notable because there are no adjustable parameters in the ammonium nitrate evaporation model. The fate of ammonium nitrate aerosol, once transported into the house, is a complex function of ventilation rate, gas phase composition, temperature, and relative humidity. Fig. 5 illustrates that appreciable indoor nitrate levels occur under 2 conditions: (1) when the temperature is low and the particle evaporation rate is reduced and (2) when the air change rate is high, increasing the rate at which particles lost to evaporation are replaced. Even for reasonably high indoor temperatures, large air change rates can result in appreciable indoor ammonium nitrate concentrations, as reflected in the data in the period from midnight to noon on January $20^{\text {th }}$.

Figure 6 shows the model results for gaseous nitric acid calculated for the same week long period in January. The value of the deposition velocity that best fits the data is 0.56 $\mathrm{cm} / \mathrm{sec}$. Also included on the graph are two calculations performed for instantaneous particle evaporation and no particle evaporation. Neglecting particle evaporation as an indoor nitric acid source results in a gross under-prediction of the measured concentrations. Conversely, neglecting the evaporation kinetics and assuming instantaneous particle evaporation overestimates the nitric acid concentration during periods with high ventilation rates and low temperatures.

The current field project was conducted during the fall and winter months to coincide with the California Regional Particulate Air Quality Study (CRPAQS), which focused on capturing the high particulate loading events that occur during the winter in the region. It is interesting to speculate how the ammonium nitrate behavior might change during other seasons. The chemical mix of PM2.5 in the summer is very different than during the winter, and in general the overall particle concentrations are much smaller. In the late spring through early fall, the San Joaquin Valley experiences much warmer temperatures, which leads to reduced concentrations of ammonium nitrate. Indoor temperatures will be similar as those observed during the winter, or larger if the residence does not have air conditioning, meaning that particle evaporation times will be at least the same order of magnitude if not faster than those presented above. The loss of nitric acid to indoor surfaces will continue at the same rate, and will continue to drive particle loss indoors. The only significant difference between cooler winter conditions and the warmer summertime is a greater likelihood that windows and doors may be left open. This can result in large air change rates in the residence and similar indoor and outdoor meteorology. Dissociation rates will be much reduced, and while nitric acid will still be 
lost to surfaces, the increased ventilation rate will result in indoor/outdoor ratios of nitrate that can approach unity.

There are few other studies that have simultaneously measured both indoor and outdoor particulate nitrate (Sinclair 1985, Sinclair 1988, Brauer 1991, Suh 1994, Allen 1995, Hering 1996). Sinclair $(1985,1988)$ and Brauer (1991) both found that measured indoor/outdoor ratio of nitrate was lower than that measured for sulfate, indicating an additional loss term consistent with the dissociation and evaporation of ammonium nitrate indoors. The difference between the indoor and outdoor levels in the study by Brauer (1991) during the summer was much smaller than that measured during the winter. This study was performed on multiple houses in the Boston metropolitan area and it was specifically stated that air conditioning was not used during the study period. This would imply that windows were probably open during the warm summer period, resulting in high air change rates and a limited temperature differential between indoors and outdoors. Based on the modeled results, this condition would result in elevated indoor nitrate levels compared to a more sealed house.

The results of Suh (1994) and Allen (1995) both showed higher indoor concentrations of nitrate aerosol compared to outdoor levels. The two investigations were conducted in Pennsylvania and Brazil, respectively. In both studies, the nitrate concentrations were significantly lower than those measured in the present study. Nitrate aerosol is highly susceptible to artifact error, which may be a factor at the low levels measured in these studies. In addition, not all PM-2.5 nitrate is ammonium nitrate and the nitrate measured in these studies could be in a different chemical form.

Many previous investigators have found that indoor concentrations of nitric acid are significantly lower that those measured outdoors (Salmon 1990, Hisham 1991, Brauer 1991, Allen 1995, Suh 1994). Suh (1994) found that the indoor concentration of HNO3 did increase with increasing air change rate, consistent with the present results. Salmon (1990), and Hisham (1991) also found that older buildings with high air change rates or climate control system had higher indoor concentrations of HNO3. Brauer (1991) found a higher indoor/outdoor ratio of nitric acid during the same summer period mentioned above, when air change rates were probably elevated.

Salmon (1990) measured nitric acid uptake by the walls in a series of museums in Southern California and found that in some of the buildings, the measured flux exceeded 
the amount of HNO3 entering the building with the ventilation air. Southern California also experiences very high levels of ammonium nitrate aerosol. This result strongly suggests that the dissociation of ammonium nitrate was an additional source of nitric acid in these experiments. The researchers used their flux measurements combined with the gas phase concentration measurements to calculate apparent deposition velocities to vertical surfaces. Their calculations resulted in deposition velocities ranging from 0.24 to $1.34 \mathrm{~cm} \mathrm{~s}^{-1}$, which is the same order of magnitude as the present value of $0.56 \mathrm{~cm} \mathrm{~s}^{-1}$ calculated by best fit of the model results to the measured indoor nitric acid concentrations. The predicted values of the diffusion limited deposition velocity range from 0.18 to $0.3 \mathrm{~cm} \mathrm{~s}^{-1}$ for friction velocities ranging from 0.3 to $0.5 \mathrm{~cm} \mathrm{~s}^{-1}$ (Cano-Ruiz 1993, Morrison 2002). We believe that the problems encountered when measuring nitric acid concentration (Fischer 2003) bias our calculated results so that they are greater than the theoretical maximum values.

Modeling indoor ammonia is much more complicated than either ammonium nitrate aerosol or nitric acid. Ammonia is much more complex than nitric acid, and its sorption, desorption, and reactions are more strongly dependent upon the variables that characterize the house. For instance, no single deposition velocity can successfully describe the measured time-resolved ammonia concentrations. Current investigations are concerned with determining the transport and fate of ammonia in the indoor environment, and will be the subject of a follow on publication.

\section{CONCLUSIONS}

We performed a series of simultaneous indoor and outdoor measurements at a residence, providing real-time, chemically speciated data for the significant aerosol species of nitrate, sulfate, and carbon as well as the gas species ammonia and nitric acid. The highly time resolved data show considerable variability in both the outdoor and indoor concentrations of PM-2.5 constituents. This results in a wide range of ratios of indoor to outdoor concentrations that might not be apparent in lower time resolved measurements. More importantly, the dissociation and evaporation of the nitrate aerosol reduced indoor concentrations significantly. A simple mass balance model that accounts for the kinetics of ammonium nitrate evaporation performs well, reproducing both the measured indoor ammonium nitrate and nitric acid concentrations. The fitted deposition velocity for nitric acid of $0.56 \mathrm{~cm} \mathrm{~s}^{-1}$ agrees well with previous measurements. 
These results suggests that exposure assessments based on total particle mass measured outdoors may obscure the actual causal relationships, especially for indoor exposures to particles of outdoor origin. These results indicate that indoor exposure to outdoor nitrate in the San Joaquin Valley is small. Nitrate is a significant outdoor pollutant in the Western United States; ammonium nitrate concentrations are especially high during the winter in California's Central Valley, and can often be the dominant aerosol. As sulfur emissions are reduced in other regions of the United States, nitrate aerosol will also constitute an increasingly significant potion of the aerosol mass in other regions. The extent to which ammonium nitrate may or may not be a significant source of indoor exposure has important policy implications for control of sources that lead to nitrate formation. These results emphasize the need for chemical characterization of particulate and further studies of the physical and chemical transformation processes that influence the indoor concentration of particles of outdoor origin.

\section{ACKNOWLEDGEMENTS}

The authors dedicate this paper in memory of Dr. Joan Daisey, who played a key role in the initial phases of this project, and whose vision has guided our work. This research was supported by the Assistant Secretary for Fossil Energy, Office of Natural Gas and Petroleum Technology, through the National Petroleum Technology Office under U.S. Department of Energy Contract No. DE-AC03-76SF00098 and the Western States Petroleum Association.

\section{REFERENCES}

Allen, A.G., and Miguel, A.H. (1995) Indoor organic and inorganic pollutants: In-situ formation and dry deposition in southeastern Brazil. Atmospheric Environment 29(23), 3519-3526.

Brauer, M., Koutrakis, P, Keeler, G.J., and Spengler, J.D. (1991) Indoor and outdoor concentrations of inorganic acidic aerosols and gases. J. Air Waste Manage. Assoc. 41, 171-181.

Cano-Ruiz, J.A., Kong, D., Balas, R.B., and Nazaroff, W.W. (1993) Removal of reactive gases at indoor surfaces: Combining mass transport and surface kinetics. Atmospheric Environment 27A(13), 2039-2050.

Chow, J.C., Watson, J.G., Lowenthal, D.H., Solomon, P.A., Magliano, K.L., Ziman, S.D. and Richards, L.W. (1993) PM-10 and PM-2.5 compositions in California's San Joaquin Valley. 
Dassios, K.G. and Pandis, S.N. (1999) The mass accommodation coefficient of ammonium nitrate aerosol. Atmospheric Environment 33, 2993-3003.

Dockery D.W., Pope C.A., Xu X.P., et al. (1993) An association between air pollution and mortality in six United-States cities. New England Journal of Medicine Vol. 329, pp 1753-1759.

Fischer, M.L., Littlejohn, D., Lunden, M.M., and Brown, N.J. (2003) Automated measurements of ammonia and nitric acid in indoor and outdoor air. Environ. Sci. Techol. In press.

Fuchs, N.A. and Stutgin, A.G. (1971) High dispersed aerosols. In Topics in Current Aerosol Research (Part 2), G.M. Hidy and J.R. Brock, eds. Pergamon, New York, 1200.

Hering, S.V. and Avol E. (1996) Indoor-outdoor concentration ratios for fine particle mass and inorganic ions in twelve southern California homes. Proceedings of the Second Colloquium on Particulate Air Pollution and Human Health (Park City, Utah, May 1-3, 1996) 3-52.

Hisham, M.W.M. and Grosjean, D. (1991) Air pollution in Southern California museums: Indoor and outdoor levels of nitrogen dioxide, peroxyacetyl nitrate, and chlorinated hydrocarbons. Environ. Sci. Technol. 25, 857-862.

Jenkins P.L., Phillips T.J., Mulberg E.J., et al. (1992) Activity patterns of Californians: Use of and proximity to indoor pollutant sources. Atmospheric Environment 26A, 2141-2148.

John, W., Wall, S.M., Ondo, J.L., and Winklmayr, W. (1990) Modes in the size distributions of atmospheric inorganic aerosol. Atmospheric Environment 24A(9), 2349-2359.

Lunden, M.M., Thatcher, T.L., Hering, S.V., and Brown, N.J. (2003) The use of timeand chemically-resolved particulate data to characterize the infiltration of outdoor PM-2.5 into a residence in the San Joaquin Valley. Submitted to Environ. Sci. Technol.

Morrison, G.C. and Nazaroff, W.W. (2002) The rate of ozone uptake on carpet: mathematical modeling. Atmospheric Environment 36, 1749-1756.

NARSTO (2003). Particulate Matter Science for Policy Makers: A NARSTO Assessment. McMurry, P., Shepher, M. and Vicker, J (Eds.) EPRI, Palo Alto, CA, USA.

Pope C.A., Bates D.V., and Raizenne M.E. (1995) Health effects of particulate air pollution: Time for reassessment? Environmental Health Perspectives 103, 472-480. 
Salmon, L.G., Nazaroff, W.W., Ligocki, M.P., Jones, M.P. and Cass, G.R. (1990) Nitric acid concentrations in Southern California museums. Environ. Sci. Technol. 24, 1004-1013.

Seinfeld, J. and Pandis, S. (1998) Atmospheric Chemistry and Physics John Wiley \& Sons, New York.

Sinclair, J.D., Psota-Kelly, L.A. and Weschler, C. (1985) Indoor/outdoor concentrations and indoor surface accumulations of ionic substances. Atmospheric Environment 19, 315-323.

Sinclair, J.D., Psota-Kelly, L.A. and Weschler, C.J. (1988) Indoor/Outdoor ratios and indoor surface accumulations of ionic substances at Newark, New Jersey. Atmospheric Environment 22, 461-469.

Stelson, A.W. and Seinfeld, J.H. (1982) Relative humidity and temperature dependence of the ammonium nitrate dissociation constant. Atmospheric Environment 16(5), 983-992.

Stolzenburg M.R. and Hering S.V. (2000) Method for the automated measurement of fine particle nitrate in the atmosphere. Environmental Science and Technology Vol. 34, pp. 907-914.

Suh, H.H., Koutrakis, P. and Spengler, J.D. (1994) The relationship between airborne acidity and ammonia in indoor environments. Journal of Exposure Analysis and Environmental Epidemiology 4(1), 1-22.

Tang, I.N., Wong, W.T. and Munkelwitz, H.R. (1981) The relative importance of atmospheric sulfates and nitrates in visibility reduction. Atmospheric Environment 15(12), 2463-2471.

Thatcher, T.L., Lunden, M.M., Sextro, R.G., et.al. (2002) The effect of penetration factor, deposition, and environmental factors on the concentration of PM-2.5 sulfate, nitrate and carbon indoors. Proceedings of the $9^{\text {th }}$ International Conference on Indoor Air Quality and Climate, 2002.

Wall, S.M., John, W. and Ondo, J.L. (1988) Measurement of aerosol size distributions for nitrate and major ionic species. Atmospheric Environment 22(8), 1649-1656.

Wallace, L. (1996) Indoor particles: A review. J. Air \& Waste Manage. Assoc. 46, 98126.

Weschler, C.J. and Shields, H.C. (1997) Potential reactions among indoor pollutants. Atmospheric Environment 31(2), 3487-3495.

Weschler, C.J. (2000) Ozone in indoor environments: Concentration and chemistry. Indoor Air 10, 269-288. 
Lunden et al.

Wexler, A.S. and Seinfeld, J.H. (1990) The distribution of ammonium salts among a size and composition dispersed aerosol. Atmospheric Environment 24A(5), 1231-1246. 


\section{Figure Captions}

Figure 1. Measured concentrations of indoor (solid line) and outdoor (dashed line) sulfate, and nitrate for two two-day periods during the October and December intensive measurements. The lower panels on the diagram show the ventilation rate and indoor temperature as a function of time.

Figure 2. Measured concentrations of ammonium nitrate particulate $\left(\mathrm{NH}_{4} \mathrm{NO}_{3}\right)$ and gaseous ammonia $\left(\mathrm{NH}_{3}\right)$ measured outside and inside the residence. The lower portion of the graph shows the concentration of the gaseous nitric acid $\left(\mathrm{HNO}_{3}\right)$ inside the residence. The numbered periods are described in the text.

Figure 3. Calculated time in minutes required for complete evaporation of a $0.5 \mu \mathrm{m}$ ammonium nitrate particle as a function of temperature and ammonia concentration for nitric acid concentrations of (a) $0.1 \mathrm{ppb}$ and (b) $0.2 \mathrm{ppb}$.

Figure 4. Evaporation rate calculated as a function of time for the January intensive measurement period. The bottom panel shows the ventilation rate (dashed line) and indoor temperature (solid line) as a function of time.

Figure 5. Measured concentrations of indoor (solid line) and outdoor (dotted line) ammonium nitrate and modeled results (dashed line) as a function of time for the January intensive measurement period. The bottom panel shows the ventilation rate (dashed line) and indoor temperature (solid line) as a function of time.

Figure 6. Measured (thick solid line) and modeled (thin solid line) concentrations of nitric acid as a function of time for the January intensive measurement period. Also shown are modeled results with instantaneous ammonium nitrate evaporation (short dashed line) and no particle evaporation (longer dashed line). The bottom panel shows the ventilation rate (dashed line) and indoor temperature (solid line) as a function of time. 


\section{Figure 1}

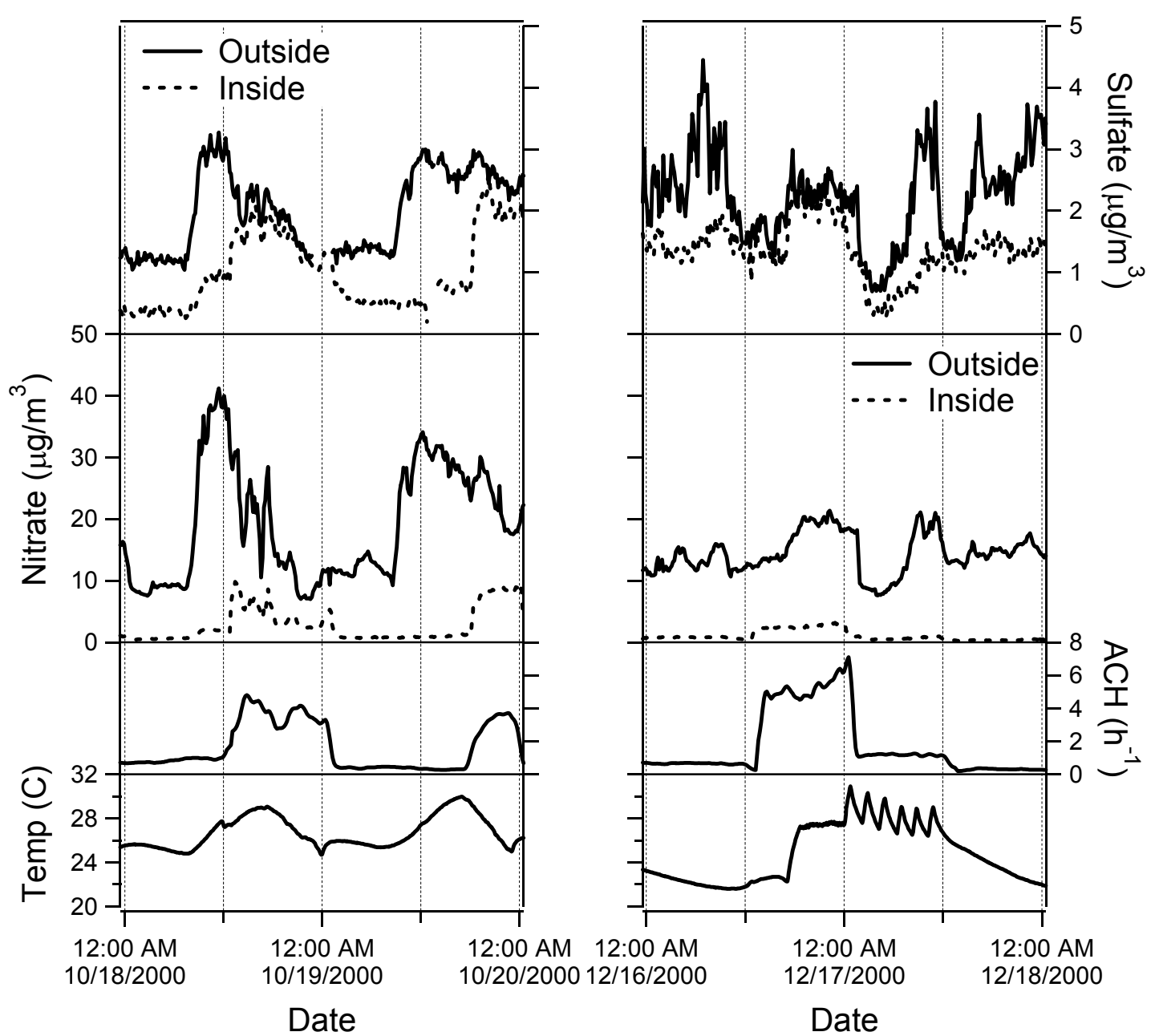


Figure 2

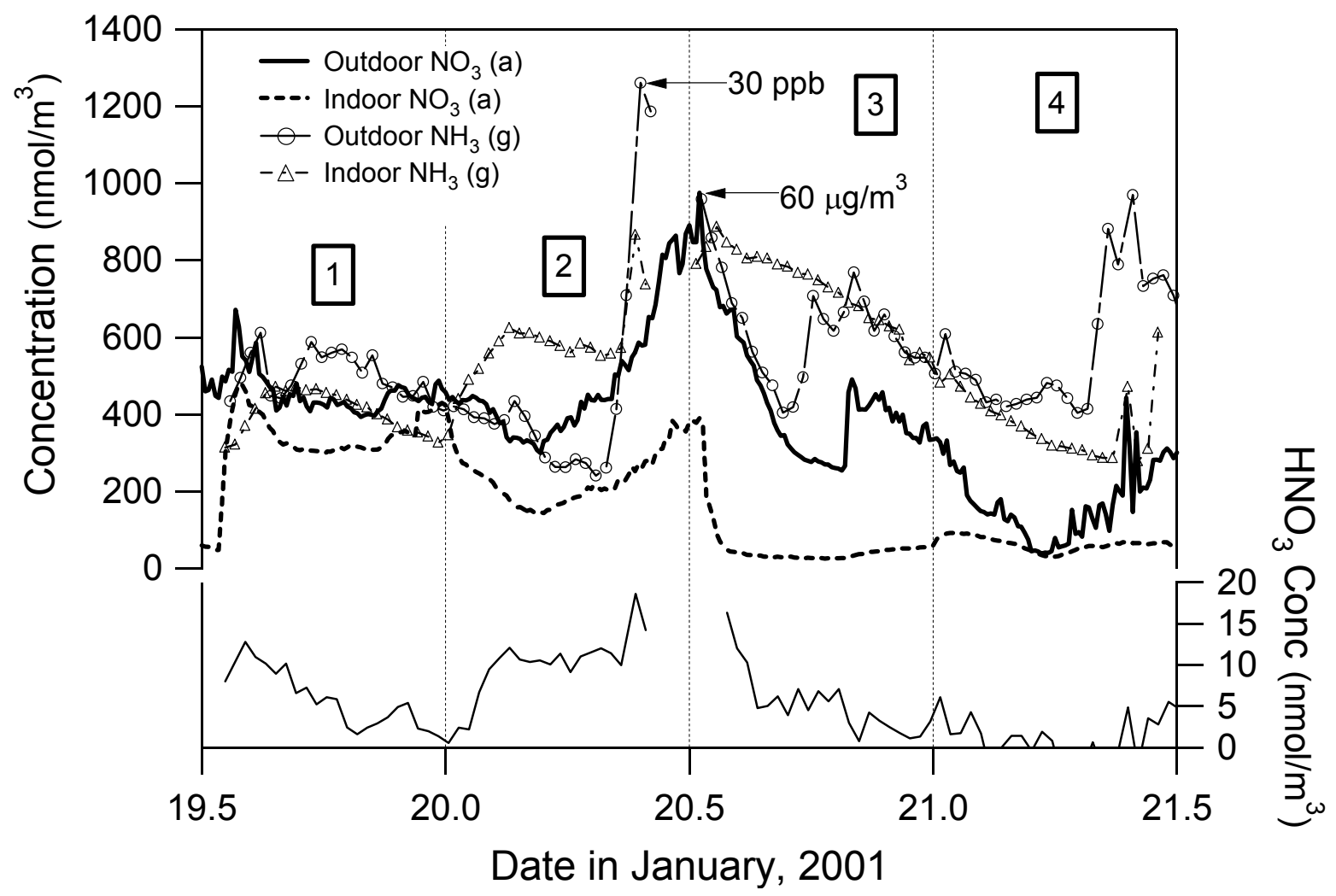




\section{Figure 3}
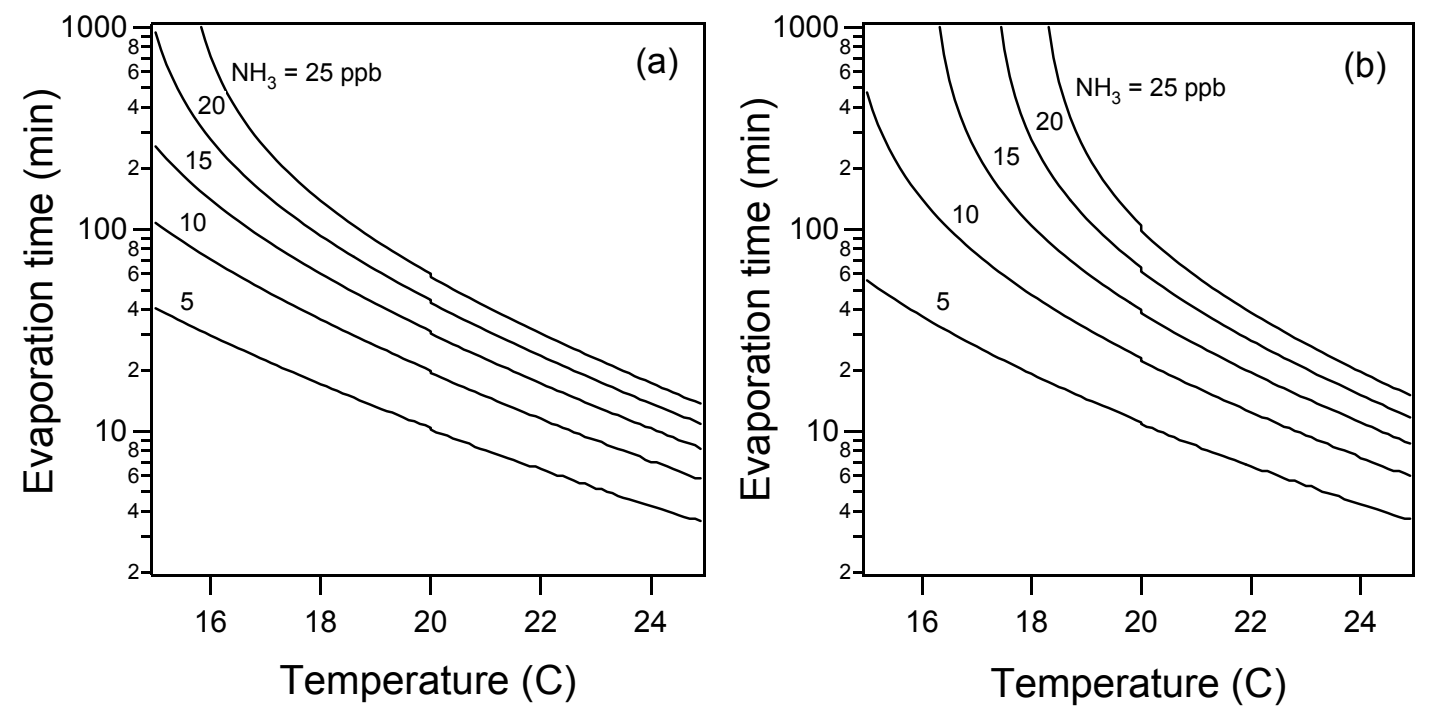
Accepted for Publication in Atmospheric Environment (Also LBNL \# 52795)

July 15,2003

Lunden et al.

Figure 4

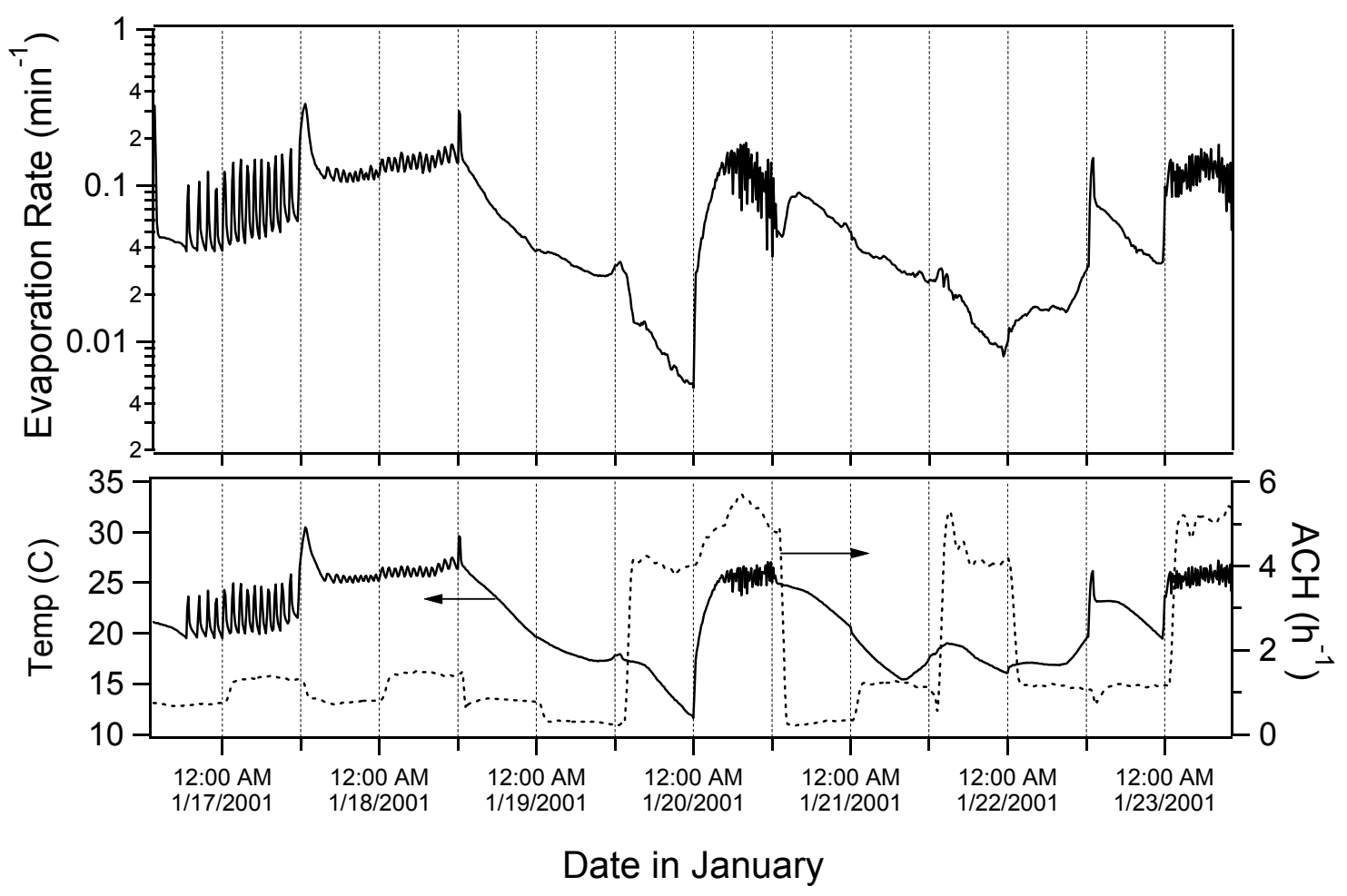


Accepted for Publication in Atmospheric Environment (Also LBNL \# 52795)

July 15,2003

Lunden et al.

Figure 5

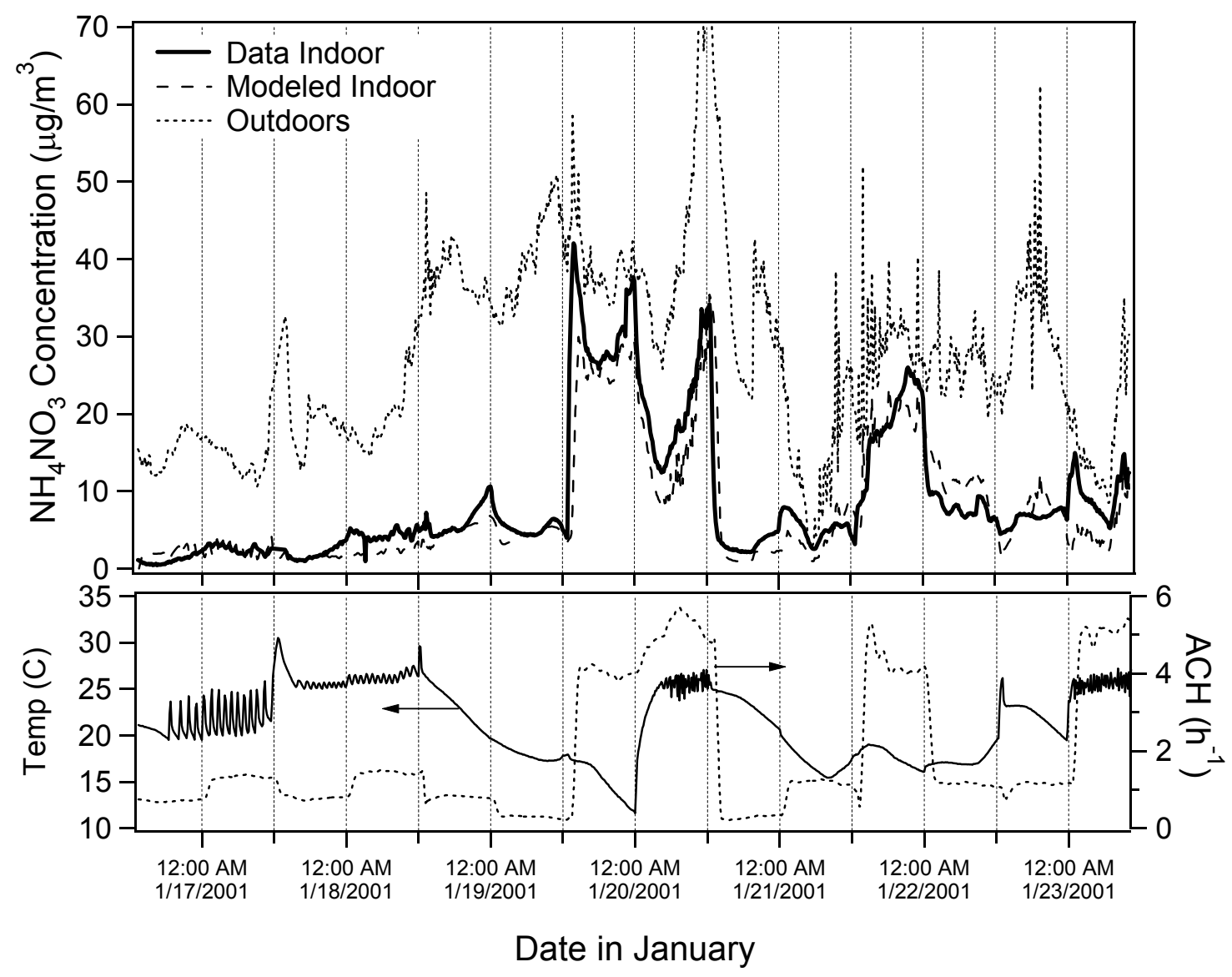


Accepted for Publication in Atmospheric Environment (Also LBNL \# 52795)

July 15,2003

Lunden et al.

Figure 6

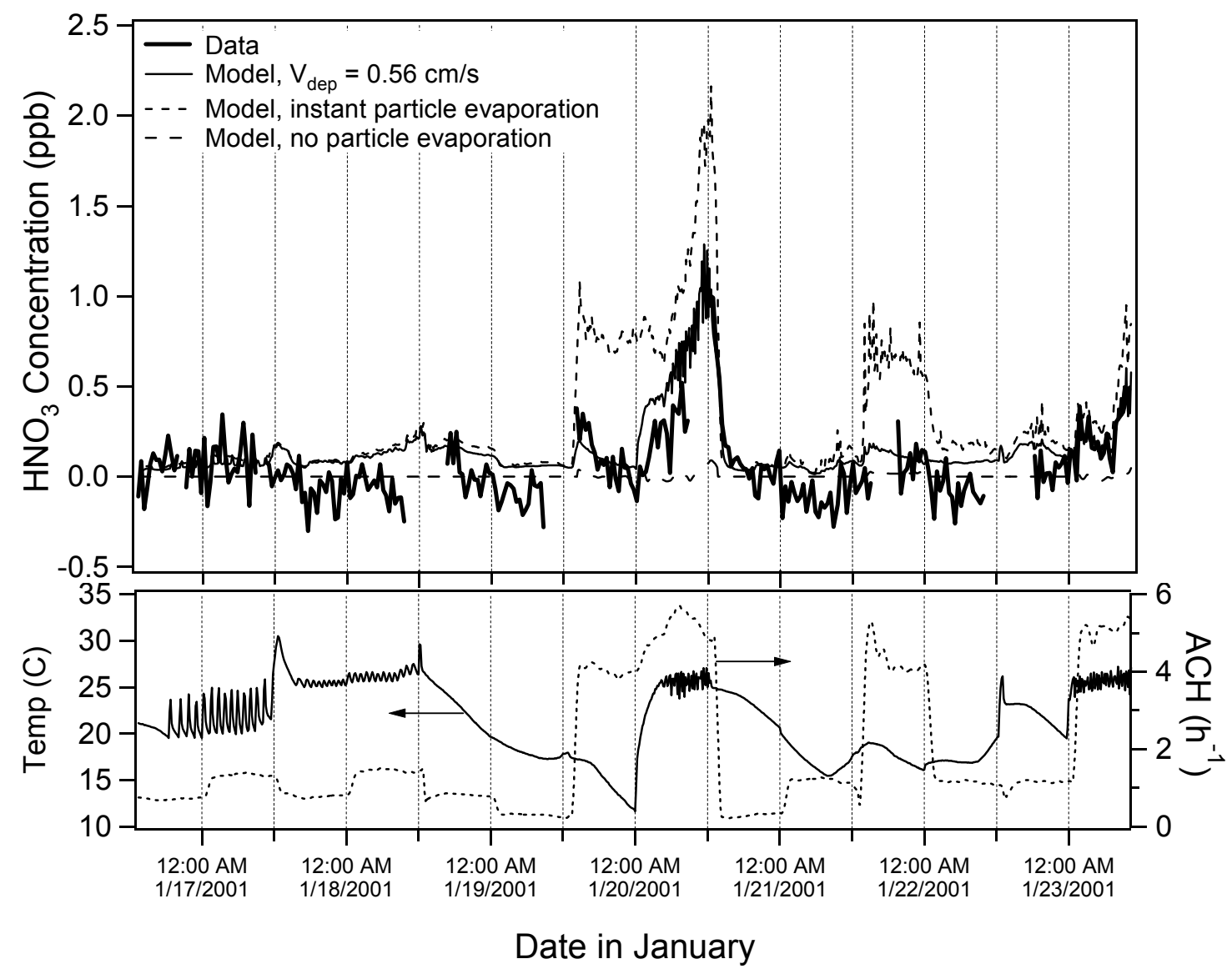

